\title{
Fixação, idiomaticidade e composicionalidade: a unidade fraseológica "deixar a poeira baixar" no português
}

DOI: http://dx.doi.org/10.21165/el.v50i2.2959

\section{José Roberto Prezotto Júnior ${ }^{1}$}

\section{Resumo}

Concebemos a Fraseologia como interdisciplinar e estabelecemos diálogo com a Linguística Cognitiva (GURILLO, 1997; 2001; OLZA MORENO, 2011; MERINO GONZÁLEZ, 2015) a fim de descrever, sincronicamente, a unidade fraseológica "deixar a poeira baixar" no português, que denota uma ordem ou um conselho do locutor ao interlocutor, para que este aguarde o fim das situações conflitantes. Utilizamos o Corpus do Português (DAVIS; FERREIRA, 2016) para análise e defendemos a hipótese de que esse fraseologismo surge da metáfora conceitual: ADVERSIDADE É DEVIDO AO TEMPO RUIM, relacionada às condições climáticas. Ademais, ratificamos a fixação e a idiomaticidade dessa unidade, por seguir a ordenação formal dos verbos modais do português e ser dotada de composicionalidade motivada, uma vez que recuperamos pistas da contribuição de seus componentes para o significado total.

Palavras-chave: unidade fraseológica; fixação; idiomaticidade; metáfora.

1 Universidade Estadual Paulista "Júlio de Mesquita Filho" (UNESP), São José do Rio Preto, São Paulo, Brasil; prezotto.jr@unesp.br; https://orcid.org/0000-0002-7077-543X 


\title{
Fixation, idiomaticity and compositionality: the phraseological unit deixar a poeira baixar in Portuguese
}

\begin{abstract}
We conceive Phraseology as interdisciplinary and we establish a dialogue with Cognitive Linguistics (GURILLO, 1997; 2001; OLZA MORENO, 2011; MERINO GONZÁLEZ, 2015) to describe, synchronically, the phraseological unit "deixar a poeira baixar" in Portuguese. This unit denotes an order or some advice from the speaker to the interlocutor, so he can wait for the end of conflicting situations. We used Corpus do Português (DAVIS; FERREIRA, 2016) for analysis and we support the hypothesis that this unit arises from the conceptual metaphor: ADVERSITY IS DUE TO BAD WEATHER, related to the weather conditions. Moreover, we ratify the fixation and idiomaticity of this unit because it follows the formal ordination of Portuguese modal verbs; and it is endowed with motivated compositionality since we can recover clues in how its components parts contribute towards the whole meaning.
\end{abstract}

Keywords: phraseological unit; fixation; idiomaticity; metaphor.

\section{Introdução}

No âmbito dos estudos linguísticos, a Fraseologia investiga as combinações, mais ou menos, fixas de lexias, buscando caracterizar sua morfossintaxe e descrever seus significados e seus contextos de uso, tanto em perspectiva sincrônica quanto em perspectiva diacrônica. Quando nos propomos a investigar uma unidade fraseológica, doravante UF, estamos, necessariamente, remetendo nosso olhar para outras disciplinas afıns que também se interessam pelo estudo em questão. Em vista disso, compreendemos a Fraseologia como interdisciplinar, um ponto de síntese entre as disciplinas de linguística: Fonologia, Morfologia, Sintaxe, Semântica, Pragmática, Lexicologia, Sociolinguística e Psicolinguística (RUIZ GURILLO, 1997).

Aliados a essa visão, seguimos os estudos de Ruiz Gurillo (1997, 2001), Olza Moreno (2011) e Merino González (2015), que mostram a possibilidade de relacionar as premissas teórico-metodológicas da Fraseologia com as da Linguística Cognitiva, visto que "o estudo fraseológico e cognitivo nos permite dar conta da aparição, criação e fixação da combinação fixa de palavras através de mecanismos figurativos, especificamente, da metáfora e da metonímia²" (MERINO GONZÁLEZ, 2015, p. 222, tradução nossa3).

\footnotetext{
2 No original: "el estudio fraseológico y cognitivo nos permite dar cuenta de la aparición, creación y fijación de la combinación fija de palabras a través de los mecanismos figurativos, en concreto, de la metáfora y la metonímia.".
}

3 Todas as traduções apresentadas neste artigo são de nossa autoria. 
Então, objetivamos, neste trabalho, descrever e analisar a UF "deixar a poeira baixar"4 no português em perspectiva sincrônica. A hipótese defendida é a de que esse fraseologismo se constrói a partir de uma metáfora conceitual relacionada às condições climáticas, veiculando o sentido de ordem ou conselho do locutor ao interlocutor, solicitando que este se acalme e espere o fim das situações que o afligem.

Nossa proposta se apropria dos métodos quantitativo e qualitativo para a análise de dados empíricos baseada em corpus e arrola parâmetros que conjugam as propriedades fraseológicas de fixação e de idiomaticidade (RUIZ GURILLO, 1997; ZULUAGA, 1980; 1975) com o conceito de metáfora conceitual (LAKOFF; JOHNSON, 1980; CUENCA; HILFERTY, 2007), indagando-se se as definições já convencionalizadas acerca dessas propriedades se aplicam total ou parcialmente em "deixar a poeira baixar".

Este artigo se encontra organizado do seguinte modo: além desta seção introdutória, apresentamos o referencial teórico e descrevemos os procedimentos metodológicos adotados; em seguida, analisamos a UF em questão e expomos as considerações finais.

\section{Referencial teórico}

\section{Fraseologia e unidade fraseológica}

A Fraseologia, enquanto estudo da combinação mais ou menos fixa de palavras, deve ser concebida como uma ciência interdisciplinar, pois, a análise de seu objeto, a UF, está, diretamente, ligada às premissas de disciplinas afins que contribuem, integralmente, para a investigação proposta pelo analista (RUIZ GURILLO, 1997).

Nos estudos fraseológicos, há oposição de duas perspectivas: ampla e estrita, ambas entendem que as UFs não são discretas e se posicionam em diferentes pontos do continuum unidade simples > combinação fixa. Em perspectiva ampla, de acordo com Gläser (1986 apud RUIZ GURILLO, 1997), no centro do sistema fraseológico, se encontram as UFs com função nominativa, indicadoras de fenômenos, objetos e ações do mundo exterior; já na periferia, se alocam as UFs com função proposicional, caracterizadas como provérbios e fórmulas rotinizadas. Zuluaga (1980) e Corpas Pastor (1996) são alguns dos representantes dessa abordagem.

Em contrapartida, em perspectiva estrita, a fraseologia delimita seu olhar às combinações exemplares de uma UF: as expressões idiomáticas. Aqui, as noções de idiomaticidade e de fixação são relevantes para a definição de UF, uma vez que, centralmente, estão

4 Embora haja uma baixa variação no segundo verbo que acompanha a unidade, optamos por apresentá-la pela forma recorrente. 
unidades mais fixas e mais idiomáticas e, perifericamente ${ }^{5}$, se localizam unidades com menos traços dessas propriedades. Ruiz Gurillo $(1997,2001)$ é uma das representantes dessa perspectiva.

Neste trabalho, não assumimos a concepção ampla ou estrita de fraseologia, em razão de não objetivarmos classificar a unidade "deixar a poeira baixar", mas de promovermos sua descrição, considerando as propriedades de fixação e de idiomaticidade, relacionando-as com o conceito de metáfora conceitual.

Portanto, seguindo a proposta de Sánchez (2008) e reconhecendo a dificuldade de precisar os limites classificatórios do objeto da fraseologia, defendemos a inclusão genérica de locuções com função sintática de elementos oracionais (nominal, verbal, adjetival, adverbial, preposicional, conjuncional), de fórmulas pragmáticas e de parêmias como UF ou fraseologismo.

\section{Propriedades das unidades fraseológicas}

"Uma sequência de palavras será considerada UF na medida em que cumpra, pelo menos, duas condições essenciais: fixação e idiomaticidade ${ }^{6 "}$ (CASTILLO CARBALLO, 1998, p. 70). Então, essas duas propriedades, definidoras do fenômeno fraseológico, são concebidas como graduais e portadoras de traços que contribuem para sua identificação. A fixação é a

[...] propriedade de certas expressões de serem reproduzidas no falar como combinações previamente feitas, como as estruturas pré-fabricadas na arquitetura. Do ponto de vista linguístico, essa propriedade pode ser definida como suspensão de alguma regra de combinação dos elementos do discurso? (ZULUAGA, 1980, p. 99).

5 Os conceitos de centro e de periferia advém da Escola Linguística de Praga. Para essa Escola, há um continuum entre elementos centrais, cujas propriedades mais caracterizam determinado fenômeno, e elementos periféricos, cujas propriedades os distanciam desse fenômeno. Então, tais noções promovem uma estruturação gradual das unidades linguísticas, mostrando que, nem sempre, os limites entre elas são estanques ou evidentes.

6 No original: "una secuencia de palabras será considerada unidad fraseológica en la medida en que cumpla, al menos, dos condiciones esenciales: fijación e idiomaticidad.".

7 No original: "propiedad que tienen ciertas expresiones de ser reproducidas en el hablar como combinaciones previamente hechas, tal como las estructuras prefabricadas en arquitectura. Desde el punto de vista de la lingüística, dicha propiedad puede ser definida como suspensión de alguna regla de la combinación de los elementos del discurso.". 
Sob esse ponto de vista, os falantes associam lexias a determinados contextos de uso, promovendo a cristalização e a convencionalização de uma sequência na língua por meio da repetição. Em outras palavras, "as UFs nascem do uso e da repetição de estruturas formadas por várias palavras (combinação livre), e a raiz do uso em contextos determinados leva à estabilidade e à fixação tanto estrutural quanto semântica ${ }^{8 \prime}$ (MERINO GONZÁLEZ, 2015, p. 230).

A ocorrência em (1) é exemplar de UF fixa. O fraseologismo "maria vai com as outras" denota um indivíduo que não tem opinião própria ou que se deixa levar pelas atitudes alheias. Essa unidade possui ordenação, totalmente, fixa, por não permitir supressão ou inserção de elementos entre as lexias que o compõe e por não possibilitar troca de tempo verbal, de gênero e do nome próprio, "maria", que o encabeça.

1. Não dá para entender qual é o seu ponto de vista a respeito da minha opinião, ou VC é maria vai com as outras ou é ignorante de fato. Foi só alguém se apresentar como coronel VC mudou sua opinião. (20abordagempolicial.com).

A segunda propriedade, idiomaticidade, é entendida como um fenômeno de base semântica em que o falante ativa associações conceituais e experiências de mundo para inferir e interpretar, pragmaticamente, o sentido expresso (MOESCHLER, 1992 apud OLZA MORENO, 2011). De acordo com Ruiz Gurillo (1997, p. 64),

[...] uma UF idiomática é uma combinação fixa de palavras que logra um significado não composicional, ocasionado por recursos como metáfora, hipérbole etc., e de uma motivação gradual que depende tanto de relações internas estabelecidas com o significado originário de seus componentes quanto de conexões contextuais externas $^{10}$.

Conforme afirma a definição acima e outros estudos na literatura (ZULUAGA, 1980; CORPAS PASTOR, 1996), é consensual incorporar à idiomaticidade a noção de não composicionalidade, argumentando que a UF de cunho idiomático tem seu significado global, sem contribuição das partes que a compõem.

8 No original: "las UF nacen del uso y repetición de estructuras formadas por varias palabras (combinación libre) y a raíz del uso en contextos determinados se llega a la estabilidad y fijación tanto estructural como semántica.".

9 Todas as ocorrências deste trabalho são oriundas do Corpus do Português (DAVIS; FERREIRA, 2016).

10 No original: "una UF idiomática es una combinación fija de palabras que disfruta de un significado no composicional, ocasionado por recursos como la metáfora, la hipérbole, etc., y de una motivación graduable que depende tanto de las relaciones internas que establezca con el significado originario de sus componentes, como de las conexiones externas contextuales.". 
Porém, a aliança entre Fraseologia e Linguística Cognitiva têm desmistificado essa alegação, especialmente, quando a UF tem como base os mecanismos cognitivos da metáfora e da metonímia. De acordo com Cuenca e Hilferty (2007), nem todo significado idiomático é opaco, ou seja, há fraseologismos idiomáticos de caráter composicional em que se evidencia a contribuição das partes para a construção de sentido. Os autores exemplificam esse fato com a UF do espanhol "tener las manos atadas", traduzida para o português, literalmente, em muitos contextos, como "estar de mãos atadas". Trazemos, então, a ocorrência em (2) da UF em português, conduzida pela explicação de Cuenca e Hilferty (2007).

2. Nós, alunos, estamos de mãos atadas porque não sabemos o que fazer. Queremos o melhor, mas está muito difícil. Peço que vocês, do governo, pensem um pouco na educação brasileira, porque nós, jovens, somos o futuro. (20educacaopublica.rj.gov.br).

Quando interpretamos a UF em (2), recorremos, primeiramente, ao conhecimento enciclopédico, por sabermos da função de nossas mãos na efetuação das mais diversas tarefas cotidianas. Então, via metonímia, associamos a capacidade de ação às mãos; caso elas estejam imobilizadas, sem possibilidade de movimento, projetamos essa situação ao fraseologismo em destaque, inferindo que os sujeitos se encontram inertes, impedidos de escapar daquele contexto, sem possibilidade de mudar a experiência vivenciada.

Segundo Cuenca e Hilferty (2007), tal inferência é a chave para interpretarmos a UF idiomática em (2) como portadora de composicionalidade motivada, pois seus componentes contribuem para a interpretação global. Logo, nos casos de composicionalidade motivada, as UFs idiomáticas não requerem, inicialmente, de interpretação literal para que, depois, se possa chegar à interpretação figurada, porque o significado idiomático decorre da imagem veiculada pelo domínio de origem, construída por processos simbólicos da cognição humana, fundamentados em diversas experiências cotidianas (GIBBS, 1990). É importante ressaltar que Cuenca e Hilferty (2007) reconhecem esse fato como complexo e ainda carente de estudos que investiguem e abram caminho para um novo entendimento de UFs metafóricas e metonímicas.

\section{Metáfora aplicada às unidades fraseológicas}

A metáfora conceitual é um mecanismo cognitivo de ordem figurativa, operante no eixo paradigmático da linguagem e se caracteriza pela experienciação de algo em termos de outro, ou ainda, da transferência unidirecional de um domínio concreto/simples (FONTE) para um domínio abstrato/complexo (ALVO). Esse processo é baseado na natureza biossocial, com inferências e motivações pragmáticas de domínios conceituais, que atendem à intenção e à expressão do falante (LAKOFF; JOHNSON, 1980). O quadro 1 traz exemplos de metáforas conceituais. 
Quadro 1. Metáforas conceituais

\begin{tabular}{|c|c|}
\hline METÁFORA CONCEITUAL & EXEMPLO \\
\hline MORRER É PARTIR & Nosso amigo nos deixou. \\
\hline TAREFAS DIFÍCEIS SÃO CARGAS & Quero tirar esse peso de mim. \\
\hline PESSOAS SÃO ANIMAIS & A mãe de Bia é uma perua. \\
\hline VIDA É UMA VIAGEM & Maria seguiu um caminho tortuoso na vida. \\
\hline TEORIAS SÃO EDIFÍCIOS & Essa teoria precisa de fundamentos empíricos. \\
\hline TEMPO É OBJETO DE VALOR & Não podemos perder tempo! \\
\hline IDEIAS SÃO ALIMENTOS & Ele ainda não digeriu essa informação. \\
\hline AMOR É GUERRA & Ela o conquistou com seu sorriso. \\
\hline
\end{tabular}

Fonte: Elaboração própria, adaptado de Cuenca e Hilferty (2007, p. 100)

Nas metáforas conceituais dispostas acima, os domínios ALVO, de natureza abstrata ("morrer", "tarefas difíceis", "pessoas", "vida", "teorias", "tempo", "ideias" e "amor"), são experienciados em termos concretos, proporcionados pelos domínios FONTE ("partir", "cargas", "animais", "viagem", "edifícios", "objeto de valor", "alimentos" e "guerra"). Desse modo, o falante transfere, analogicamente, as experiências concretas para situações abstratas.

Aplicada às UFs, a metáfora é tomada como fator de idiomaticidade, por sua participação na configuração semântica dessas unidades (OLZA MORENO, 2011), visto que "a idiomaticidade se baseia na possibilidade de tirar proveito das facetas associativas de nosso conhecimento de mundo com o intuito de projetar a situação que estas apresentam sobre outra de índole análoga"11 (CUENCA; HILFERTY, 1999, p. 119).

Então, ao projetar situações concretas vividas, há a possibilidade de o falante construir e codificar uma experiência abstrata, estruturada em termos de uma UF metafórica, dotada das propriedades de fixação e de idiomaticidade.

Esse fato está exemplificado na ocorrência em (3), com a UF "soltar a franga". Esse fraseologismo denota um significado, completamente, figurado, caracterizando um indivíduo que se mostra extravagante, sem pudores e, por vezes, pejorativamente, taxado

11 No original: "la idiomaticidad se basa en la posibilidad sacar provecho de facetas asociativas de nuestro conocimiento del mundo con el fin de proyectar la situación que éstas representan sobre otra de índole análoga.". 
de homossexual. O sentido abstrato é inferido pela metáfora conceitual PESSOAS SÃO ANIMAIS, nesse caso específico, da ave frango que se desloca de forma desengonçada e agitada. Ademais, sua fixação se comprova pela flexão de gênero do sintagma nominal "a franga", sempre no feminino, contribuindo, ainda mais, para o caráter pejorativo de tal unidade.

3. "Na festa de final de ano da empresa, então, ele soltou a franga! Bebeu em excesso, cantou, dançou, mergulhou vestido na piscina. Ele se achava o rei", relembra. (20ajudaemocional. tripod.com).

Sumariamente, mostramos que uma UF é definida por sua fıxação e idiomaticidade não composicional. Todavia, esse entendimento foi questionado, ao apontarmos que, a partir dos postulados da Linguística Cognitiva, uma UF, de ordem metafórica ou metonímica, pode exibir composicionalidade motivada.

\section{Procedimentos metodológicos}

Nesta investigação, adotamos a concepção de Fraseologia como interdisciplinar ao estabelecer diálogo com a Linguística Cognitiva (GURILLO, 1997, 2001; OLZA MORENO, 2011; MERINO GONZÁLEZ, 2015), especialmente, no que tange à noção de metáfora conceitual (LAKOFF; JOHNSON, 1980; CUENCA HILFERTY, 2007).

Para descrição de "deixar a poeira baixar", conciliamos os métodos quantitativo e qualitativo para a análise de dados empíricos baseada em corpus. Os dados foram coletados do Corpus do Português [web/dialetos] (DAVIS; FERREIRA, 2016), que considera usos reais da língua contemporânea, é composto por 1 bilhão de palavras e reúne dados de páginas eletrônicas de quatro países lusófonos (Brasil, Portugal, Angola e Moçambique) ${ }^{12}$.

A partir da entrada [deix* a poeira], que contempla todas as flexões verbais de "deixar" e permite a observação da variabilidade do verbo que vem na sequência, coletamos todas as ocorrências, referentes à UF em questão, disponíveis na amostra do português brasileiro na sincronia do século XXI. A coleta resultou em 40 ocorrências, as quais foram analisadas à luz dos parâmetros elencados no quadro 2. Esses parâmetros se baseiam nas propostas de Ruiz Gurillo (1997) e Zuluaga (1980), que caracterizam uma UF pelas propriedades de fixação e de idiomaticidade. Além disso, as ocorrências foram quantificadas, em termos de frequência/porcentagem, no programa Goldvarb $X$ (SANKOFF; TAGLIAMONTE; SMITH, 2005).

120 corpus está disponível em: http://www.corpusdoportugues.org. 
Quadro 2. Parâmetros de análise

\begin{tabular}{|c|c|l|}
\hline Propriedades & \multicolumn{2}{|c|}{ Parâmetros de análise } \\
\hline \multirow{3}{*}{ Fixação } & 1. & Fixação da ordem dos componentes. \\
\cline { 2 - 4 } & 2. & Fixação de categoria gramatical: flexão verbal. \\
\cline { 2 - 4 } & 3. & $\begin{array}{l}\text { Fixação do inventário dos componentes da UF: supressão, inserção e } \\
\text { variação de elementos. }\end{array}$ \\
\hline \multirow{2}{*}{ Idiomaticidade } & 4. & Atuação do mecanismo cognitivo da metáfora. \\
\cline { 2 - 4 } & 5. & Composicionalidade. \\
\hline
\end{tabular}

Fonte: Elaboração própria

\section{Descrição e análise de "deixar a poeira baixar"}

\section{Fixação da ordem dos componentes}

No primeiro parâmetro, referente à propriedade da fixação, almejamos verificar e explicitar a concatenação dos elementos que formam a UF em foco. De acordo com Zuluaga (1980), os fraseologismos se constroem a partir de combinações previamente feitas, ou ainda, de estruturas pré-fabricadas. Por conseguinte, a unidade sob análise se forma seguindo a estrutura sintática dos verbos modais do português: $\left[V_{1}+V_{\text {inf. }}\right]$. Especificamente, "deixar a poeira baixar" tem por base o uso de "deixar", enquanto modal deôntico orientado para o participante. Esse tipo de modalidade se refere à (não) permissão que um participante possui para executar o evento designado pelo predicado (HENGEVELD, 2004). A ocorrência em (4) explicita esse valor.

4. Falou assim, a troncos, uns bons cinco minutos; eu deixei a ir, olhando só, vivendo daquela vida que jorrava dela (18:Machado:Velha). (PREZOTTO JR., 2020, p. 70).

A característica principal da combinação de "deixar", $V_{1}$, com um verbo principal, no caso,

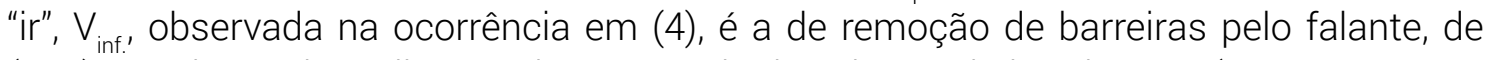
(não) permissão da realização de um estado de coisas pelo interlocutor (PREZOTTO JR., 2020). Também, notamos a força manipulativa, pela qual o sujeito permite seu alocutário, moralmente responsável, a realizar o estado de coisas "ir".

Esse contexto, a nosso ver, é a base para o surgimento do fraseologismo estudado, pois o valor de "deixar", como modal deôntico permissivo, promove a fixação dos componentes de "deixar a poeira baixar", e, por meio do mecanismo da metáfora, esses elementos se concatenam. Vejamos as ocorrências em (5) e (6). 
5. Mesmo que tenha acontecido apenas uma briga, é também indicado deixar a poeira baixar antes de falar com ele novamente. Por mais que seja difícil para você essa espera, lembre-se que se você se precipitar e ambos estiverem ainda magoados um com o outro, será impossível vocês terem um papo maduro. (20conquistarumhomem.com.br).

6. Ela disse mais uma vez q $\mathrm{n}$ tinha volta. Deixei a poeira baixar, estava planejando ir ao prédio, faculdade onde for, pedir perdão e falar q um amor verdadeiro n se acaba assim. (20papodehomem.com.br).

Ambas as ocorrências apresentam "deixar" na posição de auxiliar modal, $V_{1}$, "a poeira" como objeto direto de "baixar", que ocupa o slot de verbo principal, $V_{\text {inf. }}{ }^{13}$. Assim, o significado da UF, como exposto na introdução deste artigo, refere-se a uma ordem atenuada, um conselho, uma sugestão do falante para o ouvinte, (5), ou ainda, do próprio falante para si, (6). A ordem expressa nesse fraseologismo propõe uma atitude de calma e de espera pelo fim da situação caótica experienciada, a fim de que, posteriormente, se possa tomar uma decisão.

\section{Fixação de categoria gramatical: flexão verbal}

Neste parâmetro, averiguamos a fixação de "deixar a poeira baixar" a partir de sua flexão verbal. O único verbo da unidade que possibilita flexão é "deixar", por suas características de auxiliar, já "baixar" permanece na forma infinitiva. Na tabela 1, seguem os resultados para os tipos flexionais da UF estudada.

Tabela 1. Flexão verbal de "deixar a poeira baixar"

\begin{tabular}{c|c|c|c|c}
\hline Imperativo & Infinitivo & Gerúndio & Pretérito perfeito & Total \\
\hline $\mathbf{1 4}$ & $\mathbf{2 2}$ & 3 & 1 & 40 \\
$\mathbf{3 5 \%}$ & $\mathbf{5 5 \%}$ & $7.5 \%$ & $2.5 \%$ & $100 \%$ \\
\hline
\end{tabular}

Fonte: Elaboração própria

A tabela 1 demonstra que a forma flexional mais frequente é a de infinitivo, 55\%, seguida de imperativo, 35\%, gerúndio, 7,5\%, e pretérito perfeito, 2,5\%. Esse resultado comprova que a UF não é, totalmente, variável, uma vez que parece se restringir a determinadas flexões verbais, permanecendo mais fixa nas formas infinitiva e imperativa, exemplificadas nas ocorrências (7) e (8).

13 Por questões pragmáticas, é comum, em construções perifrásticas auxiliares que ainda não atingiram alto grau de gramaticalização, como é o caso da construção modal com "deixar", a anteposição do objeto de $V_{\text {inf. }}$ Esse fato, a nosso ver, não invalida sua fixação. 
7. Portanto, quando alguém está com raiva, você não conseguirá nada até que aquela pessoa entre em o estado oposto de paixão: a calma. Por isso, é melhor silenciar, deixar a poeira baixar e depois acertar os ponteiros. É preciso saber parar! (20eusoqueriaumcafe. com).

8. É simples, talvez as provas na faculdade e trabalho final de curso, artigo do congresso q vai participa tenha deixado ele muito confuso ele não sabe o que está sentindo, de um tempo, deixe a poeira abaixar e seja amiga dele, nessas horas todos precisão de um ombro amigo, pense nisso! (20br.answers.yahoo.com).

A flexão infinitiva, como exposta em (7), resulta do ambiente sintático em que o fraseologismo ocorre. O contexto recorrente para essa forma é o da subordinação, no qual, após orações matrizes ("é melhor", "é preciso", "é necessário", "é indicado", entre outras), "deixar a poeira baixar" se aloca, sintaticamente, no slot de uma oração encaixada.

Quando "deixar a poeira baixar" se flexiona no modo imperativo, como em (8), os resquícios do valor deôntico de "deixar" se tornam mais claros pela relação direta entre imperativo e esse tipo de modalidade, porque a expressão de ordem é tanto atributo desse modo quanto traço prototípico de deonticidade (MIRA MATEUS; DUARTE; FARIA, 2003).

Dessa maneira, nas duas flexões mais frequentes, pela herança do valor modal de "deixar", a UF denota a tentativa de um sujeito manipulador de impelir, na forma de uma ordem ou um conselho, seu interlocutor, o manipulado, para que este se tranquilize diante dos acontecimentos. Tal fato não ocorre quando "deixar a poeira baixar" se encontra no gerúndio ou no pretérito perfeito do indicativo, atentemo-nos à ocorrência em (9).

9. Quando saio com amigos e família, prefiro fingir que nada aconteceu, como que deixando a poeira abaixar e sou grata por eles entenderam esse meu modo de ser e também não ficavam perguntando e nem exigindo que minha postura fosse diferente. (20brazucasnomundo.com.br).

Na flexão de gerúndio, (9), e de pretérito perfeito, cuja única ocorrência coletada está disposta em (6), percebemos a ausência da atitude manipulativa de um falante para outro. Aqui, ao usar "deixar a poeira baixar", o próprio sujeito relata seu comportamento tranquilo diante das adversidades expressas no contexto.

\section{Fixação do inventário dos componentes da UF: supressão, inserção e variação de elementos}

Nosso intuito, nesse parâmetro, é o de averiguar a possibilidade de supressão, inserção e variação dos elementos em "deixar a poeira baixar". No que tange à supressão, o 
fraseologismo não viabiliza o apagamento de nenhum de seus componentes, isso ocorre por sua estruturação, decorrente dos verbos modais do português, $\left[\mathrm{V}_{1}+\mathrm{V}_{\text {inf }}\right]$. Além disso, a omissão de um dos elementos prejudicaria a apreensão do significado total, construído via metáfora. Testamos, na ocorrência em (10), o apagamento de um dos três componentes da UF.

10. A linguagem que nos toca o coração só pode vir do coração do outro. Simples assim. Aprendi isso. DR'S desgastam. Meu namorado sempre cala nessas horas e deixa a poeira baixar. Na verdade ele sempre cala, e demonstra como todas nós mulheres queremos (mas não nos contentamos) -- com atos, não palavras. (20nao2nao1.com.br).

10a. .... Meu namorado sempre cala nessas horas e a poeira baixar...

... Meu namorado sempre cala nessas horas e deixa baixar...

... Meu namorado sempre cala nessas horas e deixa a poeira

Como mostram os testes de (10a) a (10c), a ausência de um dos componentes não transmite o significado convencional do fraseologismo estudado. Logo, afirmamos que todos os elementos são necessários e possuem posição fixa.

Por nosso objeto ser de natureza verbal, testamos a possibilidade de inserir advérbios entre "deixar", "a poeira" e "baixar". Pela análise das ocorrências, percebemos não ser possível a inserção de elementos entre os componentes da UF, em virtude de eles se localizarem nas fronteiras da unidade. Esse caso é demonstrado nas ocorrências em (11) e (12), seguidas de seus respectivos testes.

11. A demonstração de amizade madura seria dizer algo do tipo: "Você queria tanto entrar em esse relacionamento e fico triste pela perda, agora deixa a poeira abaixar e tente se recompor devagar, no seu tempo ". (20casalsemvergonha.com.br).

11a. [...] deixa agora a poeira abaixar...

12. Calma, deixa essa loucura passar, ela vai passar. Com a música sertaneja, com a música romântica, ninguém acaba. Vai devagar, pensa em uma carreira, pensa em repertório, em um trabalho concreto, e deixa a poeira baixar um pouco. As pessoas se esqueceram completamente que quem escolhe o sucesso é o público. (20blogs.98fmcuritiba.com. br).

12a. [...] e deixa um pouco a poeira baixar...

A presença de advérbios é possível nas fronteiras (11 e 12), antes ou depois do todo fraseológico, caso um advérbio, de tempo, (11a), ou de intensidade, (12a), seja introduzido entre os slots, a fixação e o significado metafórico da UF são desfeitos, visto que as UFs "são 'reproduzidas', repetidas em bloco. O falante as aprende e as utiliza sem alterá-las ou 
decompô-las em seus elementos constituintes, repete-as como tal, como lhe disseram originalmente $^{14 \prime}$ (ZULUAGA, 1975, p. 226).

Examinemos, agora, a possibilidade de variação entre os elementos de "deixar a poeira baixar". A partir da análise empírica de nosso objeto, reconhecemos estar diante de uma variação fraseológica. Variantes fraseológicas são "modificações de uma unidade pluriverbal que não violam seu sentido e se inserem dentro da norma"15 (CASTILLO CARBALLO, 1998, p. 74) e são, "em geral, meramente parciais: não se substitui toda a expressão, mas uma parte dela, algum ou alguns de seus componentes"16 (ZULUAGA, 1975, p. 242). As variantes de $\bigvee_{\text {inf. }}$ são exibidas na tabela 2.

Tabela 2. Variantes de $\mathrm{V}_{\text {inf. }}$ de "deixar a poeira baixar"

\begin{tabular}{c|c|c|c|c}
\hline Baixar & Abaixar & Assentar & Sentar & Total \\
\hline $\mathbf{2 5}$ & $\mathbf{8}$ & 6 & 1 & 40 \\
$\mathbf{6 2 . 5 \%}$ & $\mathbf{2 0 \%}$ & $15 \%$ & $2.5 \%$ & $100 \%$ \\
\hline
\end{tabular}

Fonte: Elaboração própria

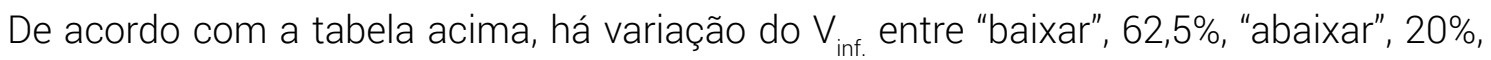
"assentar", 15\%, e "sentar", 2,5\%. Mesmo com a possibilidade de substituição do segundo verbo, estamos diante de um único campo semântico: MOVIMENTO PARA BAIXO, que não altera o sentido metafórico expresso pela UF. As quatro possibilidades de $V_{\text {inf. }}$ estão apresentadas nas ocorrências de (13) a (16).

13. E aí você começa a procurar justificativas, dizendo que estavam vivendo "um momento delicado", e que só precisa deixar a poeira baixar pra tudo voltar ao normal. Amiga, não é nada de isso também. Se você ama alguém, o "momento complicado" vai ser um desafio que vocês vão passar juntos. (20jornalmontesclaros.com).

14. O que eu amo neste programa é que eles fazem alguma cena que balança as estruturas e depois não falam sobre isso por um tempo. Você meio que deixa a poeira abaixar e depois volta a falar sobre aquilo. Não vai ter nenhum momento esquisito. (20a12.com).

14 No original: "reproducidas', repetidas en bloque. El hablante las aprende y utiliza sin alterarlas ni descomponerlas en sus elementos constituyentes, las repite tal como se dijeron originariamente.".

15 No original: "modificaciones de una unidad pluriverbal que no violan su sentido y se insertan dentro de la norma.".

16 No original: "por lo general, meramente parciales: no se sustituye toda la expresión sino una parte de ella, alguno o algunos de sus componentes.". 
15. Ora, o secretário de Segurança avisou mais uma vez o dia e hora da ocupação para dar tempo aos bandidos de saírem, e eles sabem que é só deixar a poeira assentar que poderão voltar com UPP e continuar vendendo drogas e impondo seu terror. (20blogdogarotinho.com.br).

16. Ninguém é intocável em esse mundo, até os padres, como todos, existem os bons e os mals, e se cometerem irregularidades, terão que pagar por elas, como pagaram, isso não tem nada com enganar alguém, vá se informar!!! Você tem razão, deixe a poeira sentar no Governo do Prefeito Arnaldo Mitouso. (20coariemdestaque.blogspot.com).

As ocorrências de (13) a (16) demonstram que, apesar da possibilidade de variação de um componente da UF, a substituição é fixa, isto é, os verbos que podem ocupar esse slot denotam sempre a semântica de passagem da parte superior para a parte inferior. Ao relacionarmos os quatro verbos possíveis com o sentido total da UF, atestamos que eles contribuem, figurativamente, para indicar a redução ou a erradicação de situações contrárias expressas no contexto em que a UF é usada.

Em síntese, nos parâmetros relacionados à propriedade da fixação, mostramos que "deixar a poeira baixar": (i) herda a estrutura sintática dos verbos modais; (ii) flexiona- se, frequentemente, no infinitivo e no imperativo, (iii) não permite supressão de seus três elementos nem inserção de advérbios entre eles; e, (iv) apresenta variação fraseológica, possibilitando quatro verbos na posição de $\mathrm{V}_{\text {inf.' }}$, sendo "baixar" o mais frequente.

Ressaltamos que a variação fraseológica descrita não descaracteriza a natureza fixa da UF, pois, quando a substituição é admitida, ela se restringe a alguns elementos, não indicando um menor grau de fixação nem alteração do sentido veiculado pela unidade (ZULUAGA, 1975).

\section{Atuação do mecanismo cognitivo da metáfora}

Todas as situações vivenciadas se estruturam e se consolidam, linguisticamente, em nossa cognição pelos contextos de uso e por mecanismos cognitivos, como a metáfora, que permitem transpormos experiências concretas, dos domínios físico, espacial, climático, em termos de experiências abstratas, dos domínios sentimental, temporal, social. Seguindo essa premissa, neste parâmetro, ligado à propriedade da idiomaticidade, objetivamos designar a metáfora conceitual atuante na significação de "deixar a poeira baixar". Primeiramente, atentemo-nos às informações contextuais dispostas em (17). 
17. Não corra atrás de sua amiga. Dê o tempo que ela pediu, afinal se ela pediu um tempo é porque está precisando. Deixa a poeira baixar. Olha, aqueles homens que andam pelo deserto com seus camelos, quando vem uma tempestade de areia, eles deitam se cobrindo, ficam quietinhos esperando a tempestade de areia passar, eles não enfrentam a tempestade porque sabem que irão morrer. (20maisequilibrio.com.br).

Conforme ilustra (17), o significado da UF se revela pelas experiências climáticas vivenciadas pelos seres humanos, especialmente, pelos habitantes de áreas desertas, que enfrentam constantes tempestades de areia. Consequentemente, a base concreta, tempestade de areia, se transpõe para a base abstrata, situação caótica.

A partir dessa informação contextual, depreendemos a metáfora conceitual CONDIÇÕES EXTERNAS SÃO CLIMÁTICAS (LAKOFF; ESPENSON; GOLDBERG, 1989). Essa metáfora revela a analogia que fazemos ao associar o externo ao clima; por exemplo, se o dia está ensolarado, dizemos que se trata de um bom dia, momento propício para sairmos de casa, para nos divertirmos, no entanto, quando o dia se encontra nublado ou chuvoso, dizemos que se trata de um dia melancólico ou preguiçoso, propício para ficarmos em casa. Então, expressões relacionadas ao clima são comuns para a descrição de situações cotidianas, sejam elas positivas ou negativas. Algumas dessas expressões estão explicitadas em (18) e (19).

18. A Embraer diz que mantém uma previsão favorável para o potencial do mercado chinês da aviação executiva baseada em estudos extensivos do cenário econômico do país. (20valor.com.br).

19. Daí nos casamos, comecei a curtir minha vida a dois e a observar a vida dos casais com filhos. Eu perdi completamente a vontade, não consigo pensar mais em uma só razão para ter-los. O problema é que agora eu criei um clima ruim no meu casamento, que era quase perfeito. (203xtrinta.blogspot.com).

O domínio FONTE das construções negritadas em (18) e (19) é o clima, mas, a depender da perspectiva do indivíduo, o domínio ALVO será de conquista ou de problema. Em (18), a expressão "previsão favorável" indica um bom momento para investimentos no mercado chinês, já em (19), a expressão "clima ruim" marca momentos difíceis no casamento dos referentes.

Portanto, a partir dessa metáfora conceitual genérica, emerge outra específica, ADVERSIDADE É DEVIDO AO TEMPO RUIM (LAKOFF; ESPENSON; GOLDBERG, 1989), que, a nosso ver, corresponde à UF "deixar a poeira baixar". A fim de esmiuçarmos a metáfora relacionada, especificamente, ao clima ruim, observemos o dado em (20). 
20. O mercado capitalista é assim... Se vc entrou em o vermelho, devia saber que uma tempestade esta por vir não tomou cuidado e ai de a em isso... O correto era vc não ter saido ai estourando seu orçamento. (20acertodecontas.blog.br).

A ocorrência em (20) demonstra que a condição climática ruim, "a tempestade", do domínio concreto, se transpõe para uma adversidade, "a falta de dinheiro", do domínio abstrato, experimentada pelo sujeito.

Ao aplicarmos essa metáfora conceitual à UF estudada, defendemos que o domínio FONTE se refere ao tempo ou clima ruim, que deixa o indivíduo sem reação, sem saber como agir, e o domínio ALVO diz respeito às adversidades, às situações caóticas vivenciadas por esse indivíduo, que não consegue se safar por hora, havendo necessidade de uma espera a fim de que a condição adversa passe e ele possa tomar, calmamente, as devidas decisões. A figura 2 ilustra a constituição de "deixar a poeira baixar".

Figura 1. Processo metafórico para constituição de "deixar a poeira baixar"

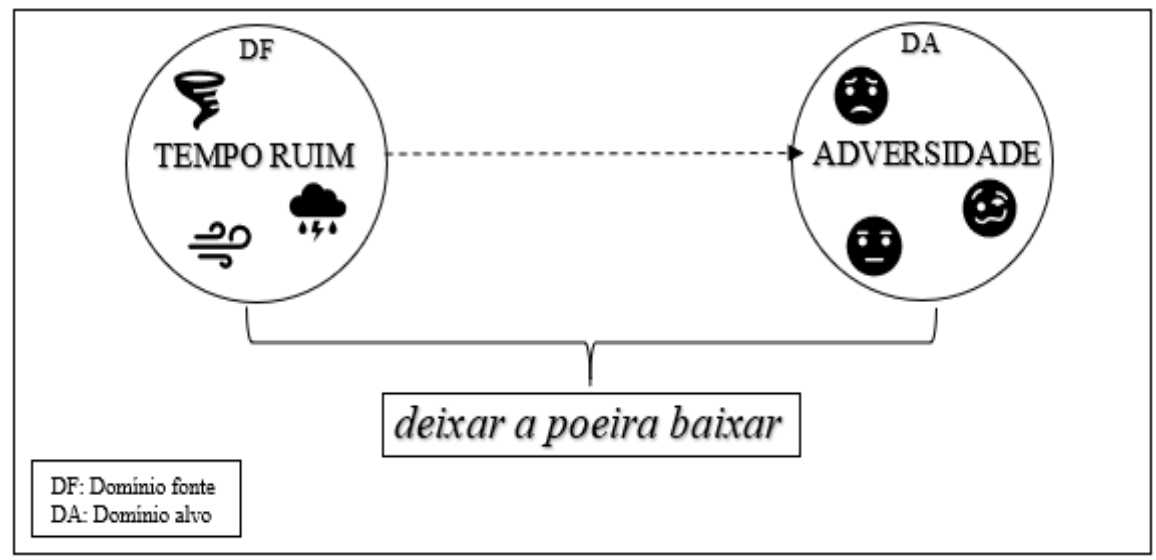

Fonte: Elaboração própria

\section{Composicionalidade}

Conforme discutido na exposição do referencial teórico deste trabalho, a idiomaticidade de uma UF se relaciona, geralmente, com o traço de não composicionalidade, quando uma combinação de duas ou mais palavras possui sentido único, sem a soma do significado individual dos componentes fixos da unidade (CASARES, 1950 apud ARRIBAS, 2014). No entanto, de acordo com Arribas (2014), esse argumento causa inúmeras controvérsias nos estudos em Fraseologia, pois nem todas as unidades possuem composicionalidade na mesma medida. Então, seguindo a alegação de Arribas (2014), discutimos, neste parâmetro, a composicionalidade de "deixar a poeira baixar". 
Retomando o questionamento de Cuenca e Hilferty (2007) sobre o tratamento de UFs idiomáticas como sinônimas de não composicionalidade, corroboramos a posição dos autores de que fraseologismos advindos de mecanismos cognitivos podem ter partes constituintes que "proporcionam as pistas necessárias para desvendar a interpretação global da expressão em questão ${ }^{17 "}$ (CUENCA; HILFERTY, 2007, p. 11818), exibindo composicionalidade motivada.

Então, no decorrer de nossa análise, mostramos indícios empíricos que comprovam a contribuição dos componentes de "deixar a poeira baixar". A ocorrência (17) é um exemplo das pistas deixadas pelas partes da UF, as quais são interpretadas por meio da analogia entre a tempestade de poeira no deserto e a adversidade vivida pelo sujeito. Consideremos a ocorrência em (21).

21. Eu tenho certeza que poderíamos, Jake, é só você ter paciência. Eu vou viajar na sextafeira, vou ficar uns dias fora e é uma boa oportunidade pra deixar a poeira abaixar. Vamos dar esse tempo pra nós dois entendermos tudo isso. Quando eu voltar, nós conversamos. (20fanficobsession.com.br).

A ocorrência em (21) se constrói no contexto de uma situação adversa: briga de casal, em que o falante sugere, ao ouvinte, um período de espera para que, posteriormente, a conversa seja retomada e a adversidade resolvida. Quando "deixar a poeira baixar" é usada para propor essa ideia, identificamos a contribuição de seus elementos na formação de seu significado: (i) "deixar", enquanto modal deôntico, contribui com a semântica de ordem, de conselho, e (ii) "a poeira baixar" contribui, figurativamente, na construção da imagem caótica instaurada pela tempestade de poeira, transferida para a situação adversa experienciada pelos referentes.

Portanto, pela cooperação das partes constituintes, sustentamos que a UF investigada é dotada de composicionalidade motivada, traço que não exclui sua natureza idiomática. A idiomaticidade se faz presente em "deixar a poeira baixar" quando, via metáfora, os usuários da língua recuperam a imagem de condição climática ruim, do domínio FONTE, e a abstratizam para expressar uma situação adversa, do domínio ALVO. Nesse processo interpretativo, os "indivíduos começam ativando o sentido composicional dado por cada um de seus constituintes, e somente, depois, chegam ao significado unitário idiomático

17 No original: "proporcionan las pistas necesarias para desentrañar la interpretación global de la expresión en cuestión.".

18 Ao lançar a proposta de composicionalidade motivada, os autores não negam nem descartam a possibilidade de arbitrariedade e de não composicionalidade de algumas unidades, pois, segundo eles, a transparência pode ir se perdendo ao longo do tempo. Ademais, o nível de transparência também depende do conhecimento dos falantes sobre o domínio FONTE daquela unidade. 
da unidade, mantendo, no entanto, ativo o conteúdo literal previamente assumido ${ }^{19}$ (CACCIARI; GLUCKSBERG, 1991, p. 219-223 apud OLZA MORENO, 2011, p. 185).

Em suma, nos parâmetros relacionados à propriedade da idiomaticidade, mostramos que o fraseologismo em foco é construído sob a metáfora conceitual ADVERSIDADE É DEVIDO AO TEMPO RUIM (LAKOFF; ESPENSON; GOLDBERG, 1989) e portador de composicionalidade motivada pela contribuição de suas partes para o significado total.

\section{Considerações finais}

Sob a concepção de Fraseologia como ciência interdisciplinar, estabelecemos diálogo com a Linguística Cognitiva, especialmente, com um de seus conceitos: a metáfora conceitual. Neste percurso, analisamos a UF "deixar a poeira baixar" no português, descrevendo as propriedades de fixação e de idiomaticidade da unidade. Argumentamos que o fraseologismo estudado tem sua gênese na metáfora conceitual ADVERSIDADE É DEVIDO AO TEMPO RUIM (LAKOFF; ESPENSON; GOLDBERG, 1989), em que o domínio FONTE, clima ruim, se transfere para o domínio ALVO, adversidade, indicando a necessidade de espera pelo fim da situação caótica para que haja possibilidade de ação.

Em termos das propriedades fraseológicas, defendemos que "deixar a poeira baixar" é fixa, por seguir a estruturação dos verbos modais do português, e idiomática, dotada de composicionalidade motivada, por surgir de uma metáfora conceitual, que possibilita a contribuição de seus componentes para o significado total.

Também mostramos que, ao recorrermos a processos metafóricos e ao evidenciarmos como experiências com o mundo refletem na língua, especificamente, na formação de fraseologismos, a definição de UF idiomática como não composicional pode ser questionada, porque "as frases feitas não são um mero saco de metáforas mortas cuja estrutura interna não tem nada a ver com sua interpretação global20" (CUENCA; HILFERTY, 2007, p. 121).

Por fim, considerando a investigação de "deixar a poeira baixar" no português brasileiro contemporâneo, delineamos encaminhamentos futuros orientados por um estudo diacrônico, que confirme a hipótese lançada sobre a emergência da UF em foco e que promova a descrição e análise de outras unidades encabeçadas por "deixar" no português,

19 No original: "los indivíduos comienzan activando el sentido composicional dado por cada uno de sus constituyentes, y solo en un momento posterior dan con el significado unitario idiomático de la unidad, manteniéndose, a pesar de todo, activo el contenido literal previamente assumido."

20 No original: "las frases hechas no son un mero saco de metáforas muertas cuya estructura interna no tiene nada que ver com su interpretación global.". 
como "não deixar a peteca cair", contribuindo, assim, para o fortalecimento da profícua união entre Fraseologia e Linguística Cognitiva.

\section{REFERÊNCIAS}

ARRIBAS, N. La fluctuante cuestión de los límites fraseológicos. AISPI Frontiere: soglie e interazioni. I linguaggi ispanici nella tradizione e nella contemporaneità, Trento, v. 2, p. 73-96, 2014.

CARBALLO, M. A. C. El concepto de unidad fraseológica. Revista de Lexicografía, v. 4, p. 67-79, 1997-1998.

CORPAS PASTOR, G. Manual de fraseología española. Madrid: Gredos, 1996.

CUENCA, M. J.; HILFERTY, J. Introducción a la lingüística cognitiva. Barcelona: Ariel, 2007.

GIBBS, R. W. Psycholinguistic studies on the conceptual basis of idiomaticity. Cognitive Linguistics, v. 1.4, p. 417-451, 1990.

HENGEVELD, K. Illocution, Mood and Modality. In: BOOIJ, G.; LEHMANN, C.; MUGDAN, J. (ed.). Morphology: A handbook on inflection and word formation. Berlin: Mouton de Gruyter, v. 2, p. 1190-1201, 2004.

LAKOFF, G.; ESPENSON, J.; GOLDBERG, A. Master Metaphor List (draft copy). Berkeley: University of California, 1989.

LAKOFF, G.; JOHNSON, M. Metaphors we live by. Chicago: Chicago University Press, 1980.

MERINO GONZÁLEZ, A. Fraseología y lingüística cognitiva. Estudio interdisciplinar de la fraseologización de la locución somática de boca en boca. EULA, v. 29, 2015, p. 221-252.

MIRA MATEUS, M. H.; DUARTE, I.; FARIA, I. R. Gramática da Língua Portuguesa. Lisboa: Caminho, 2003.

OLZA MORENO, I. Aspectos sobre la relación de idiomaticidad, metáfora y metonimia". In: SANTIBÁÑEZ, C.; OSORIO, J. Recorridos de la metáfora: cuerpo, espacio y diálogo, Concepción: Cosmigonon Editorial, 2011. p. 167-216. 
PREZOTTO JR., J. R. As microconstruções auxiliares com "deixar" e "parar" no português na expressão de aspecto final. 2020. Dissertação (Mestrado) - Instituto de Biociências, Letras e Ciências Exatas, Universidade Estadual Paulista "Júlio de Mesquita Filho", São José do Rio Preto, 2020.

RUIZ GURILLO, L. Aspectos de fraseología teórica española. Anejo XXIV de Cuadernos de filologia. Valencia: Universitat, 1997.

RUIZ GURILLO, L. La fraseología como cognición: vías de análisis. Lingüística Española Actual, XXIII/1, p. 107-132, 2001.

SÁNCHEZ, M. G. P. Introducción a la fraseología española. Estudio de las locuciones, Barcelona: Anthropos, 2008.

SANKOFF, D.; TAGLIAMONTE, S.; SMITH, E. Goldvarb X: a variable rule application for macintosh and windows. Toronto: University of Toronto, Department of Linguistics, 2005.

ZULUAGA, A. Introducción al estudio de las expresiones fijas. Max Hueber, Verlag, Tübingen, 1980.

ZULUAGA, A. La fijación fraseológica. THESAURUS, v. 30, n. 2, p. 225-248, 1975. 